\title{
Next Frontiers in Emergency Medical Services in Germany: Identifying Gaps between Academia and Practice
}

\author{
Melanie Reuter-Oppermann \\ Technical University of Darmstadt \\ oppermann@ @is.tu-darmstadt.de
}

\author{
Clemens Wolff \\ Karlsruhe Institute of Technology \\ clemens.wolff@kit.edu
}

\author{
Luisa Pumplun \\ Technical University of Darmstadt \\ pumplun@is.tu-darmstadt.de
}

\begin{abstract}
In recent years, an increase in data availability and computation power led to the "rise of Artificial Intelligence (AI)". In many different domains, AI-based methods and more specifically intelligent decision support systems (DSS) are studied in research and already implemented in practice, but not yet so in emergency medical services (EMS). This is especially true for the German EMS system that falls short in terms of digitalization in general and the use of well-grounded methods for managing and planning their logistics and processes. As the actual need for intelligent DSS in the German EMS are unclear, we have performed interviews with German EMS experts. Referring to the qualitative data, we compare the decision problems and desired DSS with existing research and identify gaps between academia and practice.
\end{abstract}

\section{Introduction}

Not only in Germany, emergency medical services (EMS) suffer from an increasing demand on the one hand and cost pressure and staff shortage on the other hand. This makes a timely provision of high quality service extremely difficult. Many regions are experiencing an increase in response times when attending to emergencies, often leading to the failure of fulfilling the response time targets. Decision support systems (DSS) based on Operations Research (OR) and Artificial Intelligence (AI), for example, as widely studied in research and already implemented in practice in many different domains, could have a significant impact on the efficiency and effectiveness of EMS systems. While in recent years, an increase in data availability and computation power led to the "rise of AI", the German EMS system still experiences major shortcomings in terms of digitalization in general and the use of well-grounded methods for managing their logistics and processes. In order to overcome these shortcomings, a timely integration of OR and AI-based applications into the EMS system is necessary. Thereby, it seems more realistic and practical to start with those applications that practitioners actively demand to use and that have already been targeted by research. With this work, we aim to establish a first overview of organizational problems that German coordination center managers and EMS staff have to face in their daily work and for which they would welcome machine-based decision support. Additionally, we want to investigate why such systems currently do not exist, even though research might already be available. Our work therefore aims to answer the following research question:

What challenges do experts face in EMS operations in Germany and how can DSS help to resolve them?

To address this research question, we created a taxonomy based on publications related to EMS operations and conducted an exploratory interview study with German EMS experts. The findings derived during those interviews give valuable insights into their daily operations and its challenges. Furthermore, we provide awareness for barriers preventing the implementation of state-of-the-art research in EMS practice as well as elaborating on avenues on how to address those. Therefore, the contribution of this work is manifold: First, this work contributes to the field of EMS, which recently has received increased attention given our changing society and crises such as the SARS-CoV-2 pandemic. Second, we contribute to EMS research by creating and presenting a taxonomy of EMS operations and possible methods of OR and AI to support decision-making. Finally, this work contributes to the transfer of academic knowledge into industry by identifying barriers preventing the implementation of state-of-the-art research findings in practice.

The remainder of the paper is structured as follows: In Section 2, we introduce the foundations for this work. Subsequently, in Section 3, we introduce this work's methodology. In Section 4, we present a taxonomy of EMS-related publications before highlighting the findings of the expert interviews in Section 5. Based on those findings, we elaborate on overarching barriers 
preventing the implementation of research findings in practice in Section 6. Finally, we reflect on this work and conclude with Section 7.

\section{Foundations}

In this section, we introduce the fundamentals of this work. In detail, we elaborate on EMS in Germany as well as intelligent DSS.

\subsection{Emergency medical services in Germany}

In Germany, patients can choose between different forms of care when experiencing a medical emergency. In case of a (life-threatening) emergency, calling 112 reaches the coordination center of an EMS region that will send an ambulance and if necessary an emergency doctor to the scene. The German EMS attend around 15 million emergencies per year [1]. In less critical cases, patients can attend out-of-hour services offered by general practitioners and registered doctors during nights and the weekends. Otherwise, patients can always walk into the emergency departments of hospitals 24/7. All these care forms are paid for by healthcare insurances which are mandatory for German residents.

In this work, we will focus on EMS. Worldwide, mainly two basic types of EMS systems can be distinguished, namely the Anglo-American and the Franco-German EMS systems [2]. One main difference lies in the staffing of vehicles. While the Anglo-American system mainly uses paramedics to staff their ambulances, the Franco-German system employs emergency medical technicians in their ambulances and send emergency doctors additionally, if necessary. Another important aspect of the German EMS system is the fact that each federal state governs its own system, leading to different structures and regulations, including response time targets, throughout the country. A further description of the German emergency system can be found in [3, 4], for example. Besides emergency rescues as their main task, EMS providers in Germany also perform non-time-critical patient transports and often offer additional services, e.g. home emergency calls.

From a process perspective, an arriving emergency call is handled as follows: the call is taken by a trained call-taker and by asking more or less standardized questions, the incident is triaged. As the vast majority of emergency calls are treated as such, the main decision is about whether or not to send an emergency doctor in addition to the ambulance. Usually, the closest available vehicles are dispatched. Note that an ambulance can in general only transport one patient. In other words, if several patients are injured in one place, several

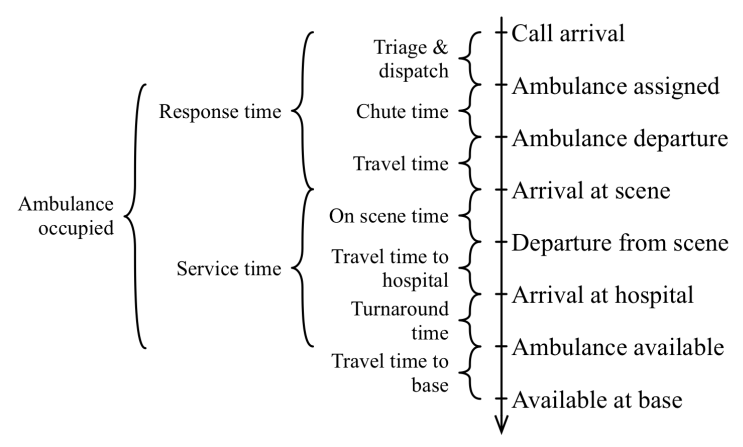

Figure 1. Process for handling an emergency call [6]

ambulances must be dispatched. Once the vehicles are assigned, they depart and head to the incident location. Note that ambulances are usually located at their designated bases when not serving an emergency, while emergency doctors are often stationed at hospitals. Having arrived at the scene, patients are treated as necessary. Once a patient is stable and ready for transport, the ambulance takes her or him to a hospital. See for example [5] for more information on this process step. If necessary, the emergency doctor accompanies the patient in the ambulance. After arrival, the patient is transferred to the emergency department of the hospital and the ambulance (and the emergency doctor) becomes available again. If no emergency is waiting to be served, the ambulance is returning to its base. An overview of this process is provided in Figure 1 and can also be found in [6] or [7], for example.

\subsection{Intelligent decision support systems}

DSS are being increasingly used to augment entire decision-making processes in organizations. In this regard, systems are programmed to prepare, supplement or partially automate decisions $[8,9,10]$. Recently, DSS have even found its way into high-risk decision situations, such as medical diagnostics or triage processes [9, 11, 12, 13]. Various research areas are concerned with the development of methods and according systems to support and relieve human decision-makers. Especially researchers in the field of OR and AI have contributed significantly to enable recent progress. These disciplines both aim at solving real-world problems, e.g. in the domain of planning, scheduling, forecasting, optimization, but differ in the approaches chosen [14]. While researchers in the field of OR use pre-defined, man-made rules and models to identify optimal or feasible solutions for well-defined problem spaces, research in AI strives to develop systems that replicate human intelligence [14, 15]. In this context, AI-methods allow for richer, more 
flexible representations of complex problems of the real world and consequently more intelligent DSS [14]. A widespread method that can be assigned to the field of $\mathrm{AI}$ is machine learning (ML). In this regard, comparably to humans, ML is able to learn from experience by itself instead of being explicitly programmed, in contrast to OR methods [16]. This is made possible by algorithms that are able to detect patterns in huge amounts of data and deduce applicable models from them $[8,17,18,16]$. Since ML is based on statistical analyses, it could lead to erroneous or biased results depending on the type, quality, and quantity of incoming data. At the same time, ML models often lack transparency as data sets and algorithms might be highly complex (e.g., large number of hidden layers in deep neural networks)[17, 8, 9]. These inherent characteristics of ML might be ethically problematic, since imprecise suggestions for decisions could remain undiscovered $[9,19]$.

\section{Methodology}

The objective of this work is to identify challenges during EMS operations in Germany and to point out possible solution approaches for decision problems known in academia, as well as implementation barriers of those in practice. To identify those challenges as well as implementation barriers to possible solution approaches, we rely on expert knowledge derived through several semi-structured interviews. In detail, industry experts highlighted challenges in their daily operations and based upon those, were presented with possible solution approaches published in academia. Subsequently, the EMS experts elaborated on whether they find those approaches helpful and reasoned why they may have not yet been implemented in practice (i.e., implementation barriers). Therefore, from a methodological perspective, this work can be separated into three phases, namely interview preparation, interview execution, and analysis. In the following, we walk through those three parts individually:

The main objective of the interviews is to identify decision problems during daily EMS operations as well as exploring possible solution approaches and barriers preventing their implementation in practice. During interview preparation, we created a taxonomy of EMS related publications on OR and AI methods. This was necessary in order to be able to respond to identified decision problems during the interviews and to discuss possible solution approaches known in academia. The taxonomy is introduced in Section 4.

After interview preparation, we conducted several semi-structured expert interviews to grasp current challenges in German EMS operations that were

\begin{tabular}{llll}
\hline Case & Role & Area & $\begin{array}{l}\text { Yearly } \\
\text { Incidents }\end{array}$ \\
\hline C1 & $\begin{array}{l}\text { coordination center } \\
\text { manager }\end{array}$ & urban & 47.000 \\
C2 & $\begin{array}{l}\text { coordination center } \\
\text { manager }\end{array}$ & rural & 50.000 \\
C3 & $\begin{array}{l}\text { coordination center } \\
\text { department manager EMS }\end{array}$ & $\begin{array}{l}\text { urban and } \\
\text { rural }\end{array}$ & 273.000 \\
C4 & $\begin{array}{l}\text { coordination center } \\
\text { department manager EMS }\end{array}$ & rural & 107.000 \\
C5 & $\begin{array}{l}\text { coordination center } \\
\text { manager } \\
\text { head of department for call } \\
\text { handling, communication } \\
\text { and simulation }\end{array}$ & urban & rural \\
\hline
\end{tabular}

Table 1. Overview of interviewed experts

followed by a qualitative analysis [20]. Since we aimed at gaining a broad understanding of decision challenges in German EMS, we applied a comparison focused sampling approach [21]. To that end, we intentionally identified experts that do come from a variety of cases with different backgrounds to consider different perspectives [22]. Overall, as displayed in Table 1, we interviewed six experts from different EMS coordination centers holding different roles. In detail, our experts all assume important roles within an EMS coordination center (i.e., center manager, department manager) and work in coordination centers of different sizes - both in regard to the area responsible for as well as the inhabitants within that area. Even though we did not explicitly interview a dedicated dispatcher, five of the six interviewed experts do have a dispatching background and still dispatch today, if required. Following common practice, the interviews were summarized and categorized before the analysis [21].

The interviews were structured in three parts: First, the experts provided information about their coordination center-e.g. size of the region covered, number of incidents handled per year-as well as their daily work in order to gain an understanding of their role and responsibilities. Based upon this description, the experts were asked to describe challenges as well as pain-points during their day-to-day business. Those were fully noted and once the list was completed, the experts were asked to rank them according to their priority. Finally, given their highlighted challenges during day-to-day operations, we walked through them individually and, if known, explained possible solution approaches for decision support (i.e., intelligent DSS) based on the previously created taxonomy (Section 
4). Once explained, we provided the experts the possibility to ask questions about the proposed solution approach, indicate whether they believe that those address the highlighted problem, and whether those could be implemented or not. Additionally, we asked the experts to elaborate on reasons why the proposed approach has not yet been implemented or what would be necessary to make it applicable for practice. Thus, the results of the interviews were two-fold: On the one hand, we derived a list of decision challenges in day-to-day EMS operations. On the other hand, we identified barriers to solution approaches to those challenges known in academia.

As mentioned, the interviews were recorded and transcribed after mutual agreement. To begin with, statements of the experts were assigned to the three parts of the interview and, if required, to the corresponding decision problem or possible solution approaches. Given the course of the interviews, statements of the second and third part of the interviews did sometimes overlap and have to be divided into current problems and possible implementation barriers to academic solutions to those problems. Starting from this broad classification of the discussed topics, transcripts were analyzed further through an iterative, multi-cycle coding process consisting of two cycles in total. In the first cycle, attribute coding was employed to obtain descriptive information of the participants and their coordination centers. Furthermore, descriptive coding was used in order to identify problems and implementation barriers from the participants' statements. In the second coding cycle, these statements are summarized via pattern coding to condense the mentioned challenges to possible solution approaches (Section 5) as well as to identify overarching gaps between practice and academia (Section 6) [23].

\section{Taxonomy for OR and AI in EMS}

As a part of the interview guideline was to specifically ask about the applicability of current research on (intelligent) DSS and the barriers for their integration into practice, a systematic overview of EMS literature mainly in the areas of OR and AI was necessary. Therefore, we have derived a taxonomy (Figure 2) by combining the call handling process (Figure 1) with existing taxonomies for EMS logistics-representing decision problems as well as logistical tasks arising for EMS management at the three planning stages, i.e. strategic, tactical and operational- [7] and for the use of OR and AI for EMS [24].

We have set up a table to present the existing literature that was used to derive the taxonomy described above. While we have prepared a longer version for the interviews, we present only a part of it here, as this is not the main focus of our work. Table 2 lists a small subset of EMS literature that was categorised to establish the taxonomy presented in Figure 2. Several surveys of OR and AI literature for EMS logistics exist that can be used to further fill the table, as for example in [7] and [25].

\section{Identified decision problems and possible solution approaches}

Table 3 provides an overview of the identified decision problems during the expert interviews. Furthermore, it lists-where possible-existing or potential approaches in the field of DSS addressing this problem from an academic perspective, as well as barriers currently preventing its implementation in practice.

The decision problem that was mentioned the most, i.e. by five out of six experts, is the problem of registering, scheduling and managing patient transports. These are non-critical transports of patients from, to or between hospitals performed by an ambulance and supervised by medically trained staff, i.e. emergency medical technicians. Currently, transports are assigned to ambulances manually throughout the day by dispatchers in the coordination centers. Hardly any day-ahead planning exists. If it does, integrating short-term demand for transports is very challenging and often not possible. Scheduling these transports is a classical OR problem and can be modelled as a so-called Dial-a-Ride Problem (DARP) [31]. Many mathematical models and solution approaches exist for the DARP, some specifically for the patient transport problem [26], many more for the general problem formulation and other logistical applications [31]. In addition, first approaches exist on how to design an intelligent DSS based on OR approaches linked to CAD [33] or a user assistance system for supporting the dispatching of ambulances to incidents [32]. Nevertheless, none of this research is currently applied in practice. Main barriers mentioned by the experts when asked for the reasons are the practitioners unawareness of this research, long process duration for developments of the operations control systems, high costs, missing collaboration between coordination centers, and missing incentives for the software companies to be innovative in the field of EMS. In addition, experts stated that underlying approaches must be transparent and dispatchers must be able to trust the system.

Three challenges have been mentioned by three experts each, two of which are related to 


\begin{tabular}{|c|c|c|c|c|c|c|c|}
\hline Ref. & Area & Output & Methods & Level & Application & Incident Type & User \\
\hline$[24]$ & Logistical & Input & ML & $\begin{array}{l}\text { Strategic, } \\
\text { Operational }\end{array}$ & Forecasting & Med. Emergencies & $\begin{array}{l}\text { Coord. Center Managers } \\
\text { Dispatchers }\end{array}$ \\
\hline$[26]$ & Organizational & Input & Optimization & Strategic & Sup. Planning & $\begin{array}{l}\text { Med. Emergencies, } \\
\text { Patient Transports }\end{array}$ & Coord. Center Managers \\
\hline$[27]$ & Logistical & Decision & Optimization & Strategic & Log. Planning & Med. Emergencies & Coord. Center Managers \\
\hline [28] & Logistical & Decision & Optimization & Operational & Dispatching & Med. Emergencies & Dispatchers \\
\hline$[29]$ & Logistical & Decision & Optimization & Strategic & Log. Planning & Med. Emergencies & Coord. Center Managers \\
\hline [30] & Logistical & Decision & Optimization & Strategic & Log. Planning & Med. Emergencies & Coord. Center Managers \\
\hline
\end{tabular}

Table 2. Exemplary Overview of Publication Addressing Intelligent DSS in EMS Logistics

\begin{tabular}{|c|c|c|c|}
\hline $\begin{array}{l}\text { Challenge or Decision } \\
\text { Problem }\end{array}$ & Case & Possible Solution Approach & Implementation Barriers \\
\hline $\begin{array}{l}\text { Handling and planning } \\
\text { patient transports }\end{array}$ & $\begin{array}{l}1,2,3 \\
4,5\end{array}$ & $\begin{array}{l}\text { - Dial-a-Ride optimization problems (e.g. [31]) } \\
\text { - simulation-based optimization (e.g. [26]) } \\
\text { - decision support and user assistance systems } \\
\text { (e.g. }[32,33])\end{array}$ & $\begin{array}{l}\text { - integration of different data sources difficult } \\
\text { - costly development } \\
\text { - lack of trust in optimization engines } \\
\text { - lack of knowledge of existing optimization } \\
\text { approaches } \\
\text { - prototypes in research not applicable in } \\
\text { practice }\end{array}$ \\
\hline $\begin{array}{l}\text { Structured emergency call } \\
\text { handling }\end{array}$ & $1,2,6$ & $\begin{array}{l}\text { - ML-based evaluation of questionnaire to } \\
\text { support triage } \\
\text { - ML-based decision whether an emergency } \\
\text { doctor is needed }\end{array}$ & $\begin{array}{l}\text { - high development costs } \\
\text { - lack of trust in IT solution }\end{array}$ \\
\hline $\begin{array}{l}\text { Routing and re-routing of } \\
\text { ambulance, time-dependent } \\
\text { dispatching }\end{array}$ & $1,4,6$ & $\begin{array}{l}\text { - } \text { shortest path optimization (e.g. }[34,35]) \\
\text { Machine }[36] \\
\text { - real-time driving time forecasts }\end{array}$ & $\begin{array}{l}\text { - routing software does not consider ambulance } \\
\text { specific characteristics (e.g. different speeds) } \\
\text { - demand not sufficient to justify development } \\
\text { costs }\end{array}$ \\
\hline $\begin{array}{l}\text { Improving coverage, } \\
\text { fulfilling response time } \\
\text { targets without additional } \\
\text { static ambulance bases or } \\
\text { ambulances }\end{array}$ & $2,3,5$ & $\begin{array}{l}\text { - location planning (e.g. [29]) } \\
\text { - ambulance relocation (e.g. [28]) }\end{array}$ & $\begin{array}{l}\text { - lack of awareness of OR approaches } \\
\text { - no cross-border planning between EMS } \\
\text { regions } \\
\text { - lack of trust in OR and ML approaches } \\
\text { - small market size prevents innovation } \\
\text { - high development costs }\end{array}$ \\
\hline Handling non-German calls & 1,6 & $\begin{array}{l}\text { - chatbots } \\
\text { - live translation based on AI methods such as } \\
\text { natural language processing }\end{array}$ & $\begin{array}{l}\text { - development costs } \\
\text { - integration of different data sources difficult }\end{array}$ \\
\hline $\begin{array}{l}\text { Computer aided dispatch } \\
\text { (CAD) system lacks } \\
\text { intelligence and support } \\
\text { for dispatchers, too much } \\
\text { information is shown } \\
\text { instead of only displaying } \\
\text { relevant information }\end{array}$ & 2,3 & $\begin{array}{l}\text { - intelligent display and personalization, as in } \\
\text { search personalization [37] } \\
\text { - ML approaches for filtering content [38] }\end{array}$ & $\begin{array}{l}\text { - difficult integration of different data sources } \\
\text { - costly development } \\
\text { - lack of trust in optimization engines } \\
\text { - lack of knowledge of existing optimization } \\
\text { approaches } \\
\text { - prototypes in research not applicable in } \\
\text { practice } \\
\text { - varying requirements from EMS regions }\end{array}$ \\
\hline $\begin{array}{l}\text { Coordination centers can } \\
\text { currently only react and } \\
\text { not proactively prepare for } \\
\text { incidents and crises }\end{array}$ & 2,3 & $\begin{array}{l}\text { - intelligent dashboard with early warning } \\
\text { system } \\
\text { - linked data sources and usage of ML } \\
\text { approaches (e.g. [24]) }\end{array}$ & $\begin{array}{l}\text { - costly development } \\
\text { - purposeful integration in existing IT solutions } \\
\text { - lack of knowledge on existing approaches } \\
\text { - lack of trust in OR and ML approaches }\end{array}$ \\
\hline expansive & 2 & - universal interfaces & - companies' interest to keep interfaces \\
\hline $\begin{array}{l}\text { Dispatching quality differs } \\
\text { for dispatchers (skills, } \\
\text { training, fitness and stress } \\
\text { level) }\end{array}$ & 4 & - dispatching approaches [28] & $\begin{array}{l}\text { - lack of knowledge on existing approaches } \\
\text { - lack of trust in OR and ML approaches } \\
\text { - small market size prevents innovation } \\
\text { - lack of coordination between regions }\end{array}$ \\
\hline $\begin{array}{l}\text { Hospital assignment time } \\
\text { consuming, unnecessary } \\
\text { transfer journeys }\end{array}$ & 4 & - emergency navigator [5] & $\begin{array}{l}\text { - lack of knowledge on existing approaches } \\
\text { - small market size prevents innovation }\end{array}$ \\
\hline Detecting similar cases & 4 & - ML-based system that detects similar cases & $\begin{array}{l}\text { - lack of knowledge on existing approaches } \\
\text { - small market size prevents innovation }\end{array}$ \\
\hline
\end{tabular}

Table 3. Overview of identified decision problems 


\begin{tabular}{|c|c|c|c|c|c|c|}
\hline Area & Medical & \multicolumn{2}{|c|}{ Organisational } & Logistical & \multicolumn{2}{|c|}{ Other } \\
\hline Output & \multicolumn{3}{|c|}{ Input for Decision Making } & \multicolumn{3}{|c|}{ Decision / Proposition } \\
\hline Methods & $\begin{array}{c}\text { Mathematical Programming / } \\
\text { Optimization }\end{array}$ & \multicolumn{2}{|c|}{ Machine Learning } & Time Series Forecasting & \multicolumn{2}{|c|}{ Other (e.g. Markov-Model) } \\
\hline Level & \multicolumn{2}{|l|}{ Strategic } & \multicolumn{2}{|r|}{ Tactical } & \multicolumn{2}{|c|}{ Operational } \\
\hline Application & Supportive Planning & $\begin{array}{l}\text { Logistical } \\
\text { Planning }\end{array}$ & Forecasting & Call Taking and Handling & Dispatching & $\begin{array}{l}\text { Incident } \\
\text { Handling }\end{array}$ \\
\hline Incident type & Medical Emergencies & \multicolumn{2}{|c|}{ Patient Transports } & \multicolumn{3}{|c|}{ Other (Disaster Management, Mass Emergency) } \\
\hline User / Beneficiary & $\begin{array}{c}\text { Coordination Center } \\
\text { Managers }\end{array}$ & \multicolumn{2}{|c|}{$\begin{array}{l}\text { Coordination Center Staff } \\
\text { (Call Takers, Dispatchers) }\end{array}$} & $\begin{array}{c}\text { Emergency Medical } \\
\text { Technicians, Emergency } \\
\text { Doctors }\end{array}$ & $\begin{array}{c}\text { First } \\
\text { Responders / } \\
\text { Volunteers }\end{array}$ & $\begin{array}{c}\text { Family / } \\
\text { Stakeholder }\end{array}$ \\
\hline
\end{tabular}

Figure 2. Taxonomy for the use of OR and Al methods in EMS

well-studied OR problems. The first targets ambulance routing, re-routing and time-dependant dispatching. Determining shortest path between two points in a (street) network is a well-studied OR problem [34] and has also already been addressed for the routing of ambulances [35]. Prerequisites for the successful application of routing algorithms in EMS practice are records and analyses of the actual ambulances' driving speeds, all possible paths and real-time information on ambulance locations, i.e. GPS information, traffic and road constructions.

The second challenge is the improvement of emergency coverage and the fulfillment of response time thresholds not only in average, but throughout the region. Here, location planning approaches as another main OR area can be applied. The strategic problem of locating ambulances and bases is the most studied EMS problem in research [7]. In addition, several papers propose approaches for relocating ambulances, as for example Andersson and Värbrand (2006) [28] or as presented in the overview by Belanger et al. (2019) [25]. Again, one of the main reasons why these approaches are not applied in German EMS is the unawareness of practitioners. Also, the few software companies on the market do not have the necessary know-how, most of them have a different background, e.g. a communication technology background. As academia usually only develops prototypes, these are not directly implementable in practice, but additional work and costs would incur. In addition, no regulations or central requirements for ambulance location exists besides the response time thresholds. Coordination centers would need to collaborate, bundle their interests and express their demands. Due to the high number of EMS regions in Germany, cross-border planning would also be necessary. Again, an applied DSS must be transparent, trustworthy and legally safe to be accepted.

\section{Steps towards resolving implementation barriers in German EMS}

Following the methodology described in Section 3, we identified six overarching challenges that need to be addressed in order to improve decision support in EMS in Germany. In the following, we walk through those individually and highlight steps that could be taken to address them.

\subsection{Demand pooling to increase market power}

German EMS are strongly fragmented. Overall, Germany is divided into 230 EMS regions that each have their own coordination center that act independently of one another. This fragmentation is also present in its IT landscape, since each coordination center makes individual decisions with regard to their IT landscape, its functionalities, as well as service provider. Whilst demand is fragmented, supply on the other hand is limited: There is only a handful of software providers offering IT solutions for coordination centers. As a consequence, a single coordination center has low power compared to the software provider with regard to the software features.

Addressing this issue, we propose to harmonize and centralize the IT landscape of German EMS. In detail, as expressed by one expert (C4), for example, an aligned IT landscape of all coordination centers in Germany would decrease costs and increase the coordination centers' market power compared to software providers. This, in turn, allows coordination centers to demand more specialized features and DSS for their software platform. 


\subsection{Ecosystem and platform design}

According to Hein et al. [39], an ecosystem is a "self-adaptable, self-contained system[s] of regularly loosed coupled economic and social actors" that are oftentimes organized around a service platform [40]. Thus, the ecosystem describes purposeful interaction of different participants, oftentimes facilitated by the platform. In EMS, participants of the EMS ecosystem are involved parties, e.g. ambulance, coordination center, as well as patients. Their interaction is mainly facilitated by the coordination center with the support of the coordination center's IT landscape serving as integrating platform, usually provided by a third-party software provider. Thus, the EMS ecosystem corresponds to a platform-driven ecosystem [41]. According to the classification of Smedlund and Faghankhani [42], this platform corresponds to a closed platform, since its access is strictly controlled by the software provider. Thus, the entire EMS ecosystem is of closed nature.

Recent research, however, indicates that open ecosystems and open platforms are a driver for innovation. To that end, Benz and Seebacher [43] argue that service systems-a service science specific term corresponding to a value co-creating configuration of resources [44] - are a driver for open innovation, i.e. a "distributed innovation process that relies on purposefully managed knowledge flows across organizational boundaries" [45]. Therefore, overall innovation is driven by opening an ecosystem to additional participants. The reasons for that are evident: New organizations can easily contribute to the overall EMS ecosystem by complementing innovations and potentially generating network effects [46]. Especially for software providers, participation in third-party platform-based ecosystem has been reported to increase revenue [47]. Whilst some platform providers may fear loss of platform control, Parker and Van Alstyne [48] argue that opening the platform and giving away intellectual property is in fact profitable. Therefore, in order to facilitate innovation in EMS operations, we argue that the EMS ecosystem should be pushed towards opening itself eventually becoming an open ecosystem with a centralized, yet open platform allowing for easy introduction of complementary services by any party. One possible approach to drive an open ecosystem may be the implementation of an open-data strategy $[49,50]$.

\subsection{Awareness}

Another barrier is the missing knowledge of coordination center managers, EMS staff and software companies about existing and potential OR and AI methods for EMS management and decision support. If coordination center managers or other EMS experts learn about existing research and their potential options for decision support, they include these in future invitations to tender for new systems and system updates. Raising awareness of practitioners is therefore an important, potentially time-consuming, but also comparatively easy task. EMS experts could be informed at symposiums, in journal articles and other publications as well as in one-on-one meetings. For all these mediums, smart ways of displaying the research should be used. With this research we have performed two first steps towards raising awareness. By asking EMS experts about the applicability of existing approaches in research we have increased their awareness. In addition, we derived a taxonomy for OR and AI methods in EMS in Section 4 for classifying and presenting intelligent DSS in EMS.

\subsection{Usability}

The processes in control centres are often complex, contain a multitude of steps, and must be run flawlessly in the shortest possible time. Nowadays, a variety of DSS are already in use within the EMS sector to support decision-making [32]. However, the experts indicate that today's systems are frequently user-unfriendly and lack an intuitive, straight-forward user interface. As a result, DSS might be rejected by potential users or the intention to continue using the system may be inhibited due to dissatisfaction [51,52]. Especially, if intelligent DSS based on complex ML models become increasingly prevalent in the future, this problem could become even more acute. Research and practice should therefore strive to make DSS more user-friendly and easy to use. In this regard, cognitive load theory could be a useful starting point to analyse current and future systems as well as user behaviour from a theoretical perspective [53]. According to cognitive load theory, user's effort to process and memorize new information is affected by a variety of determinants, for example information presentation or user familiarity with a specific system $[51,53]$. From an operational point of view, this could imply that only relevant information should be displayed by the DSS at the appropriate point of time to prevent cognitive overload. Especially in EMS, recent DSS often require the use of several monitors, inhibiting the efficient absorption of information. To live up to cognitive load theory, these should be limited to a certain number (max. up to 4 monitors according to experts). Furthermore, if several DSS exist to support decisions, they should be integrated by the help of universal 
interfaces. This allows information to be accessed at a central point to improve the comprehensibility and traceability of decisions.

\subsection{Transparency}

As providing emergency care and performing emergency rescues are the main tasks for German EMS, its focus lies on saving lives. Resources must therefore be used as efficiently as possible and all decisions must be carefully evaluated, even though decisions have to be made under severe time pressure [32]. Our interviews show that if intelligent DSS are to be used in coordination centres, it is crucial that call takers, dispatchers and other EMS staff (e.g. coordination centre managers, emergency medical technicians, emergency doctors) understand how suggestions for decisions were made. Modern intelligent DSS could fail to meet this requirement because they might be based on intransparent ML models. This is especially problematic since ML models might be trained on biased data sets. As a result, decisions supported by ML models could be subject to distortion (e.g. preferring certain groups of people in emergency rescue) $[9,19]$. In this regard, EMS staff might lack the possibility to carefully validate the decisions taken, especially as they are usually only medically trained and do not own a data science or statistical background [32]. Explaining decisions affected by intelligent DSS is therefore highly important to increase the trust and eventually the acceptance of users [54, 55, 56]. Furthermore, transparency might be legally required to deploy the intelligent DSS in EMS's everyday routine (see Section 6.6). If intelligent DSS are not designed transparently, money and resources might have been spent but systems are not used and the staff continues to make its own, usually sub-optimal, decisions. To avoid these pitfalls, research is being done at the intersection of AI, social sciences, and human-computer interaction [55]. In this context, the discipline of explainable AI aims to design assistive tools to explain a decision proposal's underlying causes to the human user in a comprehensible manner [55]. Furthermore, humans might prefer simpler, more understandable OR heuristics instead of black box ML models, even though they may own lower performances, if, for example, legal coverage is necessary in disposition decisions.

\subsection{Legal constraints}

While all federal states in Germany have individual rules and regulations, most of them have response time targets for medical emergencies that also serve as their main performance indicator. They specify an average time span for the ambulance to arrive at the scene in a defined percentage of incidents. In one federal state of Germany, for example, ambulances should arrive within at most 15 minutes from the incoming of the call in $95 \%$ of the cases. Note that there are no targets for the remaining 5\%. Due to limited resources and staff shortage, a $100 \%$ coverage is usually impossible, and many regions struggle to meet the response time targets. A DSS suggesting relocations and dispatching of ambulances would lead to suggestions on which patients will be reached in time, and which patients might have to wait longer for an ambulance, as resources would still be limited. Impacts have to be carefully considered and the aspect of fairness should be investigated, as for example in [27].

Regularly, patients or relatives sue the EMS provider, because they believe that an ambulance could have arrived earlier at the scene or an emergency doctor should have been dispatched right away. Then, the EMS provider must prove that the dispatcher made the right decision. If now this decision is based on a intelligent DSS, it must be clear how the suggestion was derived. In case it turns out that the decision was wrong, it must be possible to determine whose fault it was. Using transparent approaches and explainable AI could be one way of approaching this challenge. In addition, legal experts should be involved and developed DSS should be certified.

\section{Conclusions and outlook}

In this work we have targeted daily challenges of decision-making in German EMS operations by performing interviews with experts from German EMS coordination centers. We have derived a list of challenges, compared them to existing and potential solution approaches and have investigated barriers that have so far prevented the integration of these approaches in practice. While for many of the challenges approaches from the areas of OR and AI already exist and could be adjusted to match all needs, practice is unaware of these possibilities. High development costs, a small market science and a lack of cooperation between regions are more barriers that have been identified in this work. In addition, acceptance of and trust in these applications by the prospective users like coordination center managers or dispatchers is crucial and an absolute requirement. Therefore, transparency of the systems and the design of user assistance components are two important success factors.

One potential limitation of our work is the single perspective on Germany, as EMS systems differ between countries, in their design, as well as in the degree of 
digitalization and use of (intelligent) DSS. Although the challenges and barriers identified may not be directly transferable to other systems, the methodology used in this work is still applicable. Furthermore, the derived taxonomy that served as a basis for our interviews has a generic, international focus.

In addition, experts from only six out of around 240 coordination centers have been interviewed, leading to potentially non-representative findings. To counteract this risk, we have applied a comparison focused sampling approach [21] and substantiated our findings with existing research. However, as a next step we envision a representative survey with EMS experts from as many coordination centers as possible. As the experts stated, it will not be possible to work on all challenges related to DSS in EMS at the same time. Priorities given in the expert interviews were inconclusive and partly contradicting, demonstrating the relevance of a clear road map as depicted in this research agenda. Therefore, the survey will also be used to order the challenges. Based on the number of mentions, managing and scheduling patient transports seems to be a first promising challenge to address in future work. This challenge is particularly well suited because it bases on a well-studied OR problem. As transports are neither time-critical nor medically critical, but incur high workloads for dispatchers and EMS staff, they are an ideal starting point to address current challenges in German EMS. Besides, patients and other care providers, e.g. hospitals, ordering these transports would benefit significantly from an improved scheduling and management. Rising awareness for existing and potential research towards the application of OR and AI methods in EMS is another topic we will continue as it can also increase the acceptance of future DSS.

\section{References}

[1] IKK, "Notfallversorgung in Zahlen," tech. rep., $\quad$ https://www.ikkev.de/politik/gkv-in-zahlen/ notfallversorgung-in-zahlen/, last accessed: 13.07.2020.

[2] W. Dick, "Anglo-American vs. Franco-German Emergency Medical Services System," Prehospital and Disaster Medicine, vol. 18, pp. 29-37, 32003.

[3] F. Ahnefeld, W. Dick, P. Knuth, and H. Schuster, "Grundsatzpapier Rettungsdienst," Notfall, vol. 1, no. 2, pp. 68-74, 1998.

[4] H. Behrendt and R. Schmiedel, "Die aktuellen Leistungen des Rettungsdienstes in der Bundesrepublik Deutschland im zeitlichen Vergleich (Teil II)," Notfall \& Rettungsmedizin, vol. 7, no. 1, pp. 59-70, 2004.

[5] M. Reuter-Oppermann and C. Wolff, "Enabling Customer-Centric Emergency Logistics Through Systems Thinking," in ECIS, (Online AIS Conference), 2020.

[6] Y. Kergosien, V. Bélanger, P. Soriano, M. Gendreau, and A. Ruiz, "A generic and flexible simulation-based analysis tool for ems management," International Journal of Production Research, vol. 53, no. 24, pp. 7299-7316, 2015.

[7] M. Reuter-Oppermann, P. L. van den Berg, and J. L. Vile, "Logistics for Emergency Medical Service systems," Health Systems, vol. 6, no. 3, pp. 187-208, 2017.

[8] A. Rai, P. Constantinides, and S. Sarker, "Editor's Comments: Next-Generation Digital Platforms: Toward Human-AI Hybrids," MIS Quarterly, vol. 43, no. 1, pp. iii-x, 2019.

[9] C. Rudin, "Stop Explaining Black Box Machine Learning Models for High Stakes Decisions and Use Interpretable Models Instead," Nature Machine Intelligence, vol. 1, no. 5, pp. 206-215, 2019.

[10] P. Goes, "Big data and IS research," MIS Quarterly, vol. 38, no. 3, pp. iii - viii, 2014.

[11] M. E. Ahsen, M. U. S. Ayvaci, and S. Raghunathan, "When Algorithmic Predictions Use Human-Generated Data: A Bias-Aware Classification Algorithm for Breast Cancer Diagnosis," Information Systems Research, vol. 30, no. 1, pp. 97-116, 2019.

[12] A. Tang, R. Tam, A. Cadrin-Chênevert, W. Guest, J. Chong, J. Barfett, L. Chepelev, R. Cairns, J. R. Mitchell, M. D. Cicero, et al., "Canadian Association of Radiologists White Paper on Artificial Intelligence in Radiology," Canadian Association of Radiologists Journal, vol. 69, no. 2, pp. 120-135, 2018.

[13] J. He, S. L. Baxter, J. Xu, J. Xu, X. Zhou, and K. Zhang, "The Practical Implementation of Artificial Intelligence Technologies in Medicine," Nature medicine, vol. 25, no. 1, pp. 30-36, 2019.

[14] C. P. Gomes, "Artificial Intelligence and Operations Research: Challenges and Opportunities in Planning and Scheduling," The Knowledge Engineering Review, vol. 15, no. 1, pp. 1-10, 2000.

[15] P. R. Norvig and S. A. Intelligence, Artificial Intelligence: A Modern Approach. Prentice Hall, 2010.

[16] T. Mitchell, Machine Learning. McGraw-Hill International Editions, McGraw-Hill, 1997.

[17] E. Brynjolfsson and T. Mitchell, "What Can Machine Learning Do? Workforce Implications," Science, vol. 358, no. 6370, pp. 1530-1534, 2017.

[18] M. I. Jordan and T. M. Mitchell, "Machine Learning: Trends, Perspectives, and Prospects," Science, vol. 349, no. 6245, pp. 255-260, 2015.

[19] R. Challen, J. Denny, M. Pitt, L. Gompels, T. Edwards, and K. Tsaneva-Atanasova, "Artificial Intelligence, Bias and Clinical Safety," BMJ Quality \& Safety, vol. 28, no. 3, pp. 231-237, 2019.

[20] J. Ritchie and J. Lewis, Qualitative Research Practice. London: SAGE, 1 ed., 2003.

[21] M. Saunders, P. Lewis, and A. Thornhill, Research Methods for Business Students. Harlow: Pearson Education, 5 ed., 2009.

[22] I. Benbasat, D. Goldstein, and M. Mead, "The case research strategy in studies of information systems," MIS Quarterly, vol. 11, no. 3, pp. 369-386, 1987.

[23] J. Saldaña, The coding manual for qualitative researchers. London: SAGE, 2009.

[24] M. Reuter-Oppermann and C. Wolff, "Towards a unified understanding of data-driven support for emergency medical service logistics," in HICSS, 2020. 
[25] V. Bélanger, A. Ruiz, and P. Soriano, "Recent optimization models and trends in location, relocation, and dispatching of emergency medical vehicles," European Journal of Operational Research, vol. 272, no. 1 , pp. $1-23,2019$.

[26] Y. Kergosien, M. Gendreau, A. Ruiz, and P. Soriano, Proceedings of the International Conference on Health Care Systems Engineering, ch. Managing a Fleet of Ambulances to Respond to Emergency and Transfer Patient Transportation Demands, pp. 303-315. Cham: Springer International Publishing, 2014.

[27] C. Jagtenberg and A. Mason, "Improving fairness in ambulance planning by time sharing," European Journal of Operational Research, vol. 280, no. 3, pp. 1095 $1107,2020$.

[28] T. Andersson and P. Värbrand, "Decision support tools for ambulance dispatch and relocation," Journal of the Operational Research Society, vol. 58, pp. 195-201, Mar. 2007.

[29] M. S. Daskin, "A maximum expected covering location model: Formulation, properties and heuristic solution," Transportation Science, vol. 17, no. 1, pp. 48-70, 1983.

[30] E. T. Erdemir, R. Batta, P. A. Rogerson, A. Blatt, and M. Flanigan, "Joint ground and air emergency medical services coverage models: A greedy heuristic solution approach," European Journal of Operational Research, vol. 207, no. 2, pp. $736-749,2010$.

[31] J.-F. Cordeau and G. Laporte, "The dial-a-ride problem: models and algorithms," Annals of Operations Research, vol. 153, no. 1, pp. 29-46, 2007.

[32] M. Reuter-Oppermann, S. Morana, and P. Hottum, "Towards designing an assistant for semi-automatic ems dispatching," in HICSS, 2017.

[33] M. Reuter-Oppermann, J. Kunze von Bischhoffshausen, and P. Hottum, "Towards an IT-Based Coordination Platform for the German Emergency Medical Service System," in Exploring Services Science, vol. 201 of LNBIP, pp. 253-263, 2015.

[34] B. V. Cherkassky, A. V. Goldberg, and T. Radzik, "Shortest paths algorithms: Theory and experimental evaluation," Mathematical programming, vol. 73, no. 2, pp. $129-174,1996$.

[35] S. Humagain, R. Sinha, E. Lai, and P. Ranjitkar, "A systematic review of route optimisation and pre-emption methods for emergency vehicles," Transport reviews, vol. 40, no. 1, pp. 35-53, 2020.

[36] S. Huber and C. Rust, "Calculate travel time and distance with openstreetmap data using the open source routing machine (osrm)," The Stata Journal, vol. 16, no. 2, pp. 416-423, 2016.

[37] H. Yoganarasimhan, "Search personalization using machine learning," Management Science, vol. 66, no. 3, pp. 1045-1070, 2020.

[38] M. Chau and H. Chen, "A machine learning approach to web page filtering using content and structure analysis," Decision Support Systems, vol. 44, no. 2, pp. 482-494, 2008.

[39] A. Hein, J. Weking, M. Schreieck, M. Wiesche, M. Böhm, and H. Krcmar, "Value co-creation practices in business-to-business platform ecosystems," Electronic Markets, vol. 29, no. 3, pp. 503-518, 2019.
[40] A. Tiwana, B. Konsynski, and A. A. Bush, "Research Commentary-Platform Evolution: Coevolution of Platform Architecture, Governance, and Environmental Dynamics," Information Systems Research, vol. 21, no. 4, pp. 675-687, 2010.

[41] J. T. Eckhardt, M. P. Ciuchta, and M. Carpenter, "Open innovation, information, and entrepreneurship within platform ecosystems," Strategic Entrepreneurship Journal, vol. 12, no. 3, pp. 369-391, 2018.

[42] A. Smedlund and H. Faghankhani, "Platform Orchestration for Efficiency, Development, and Innovation," in HICSS, pp. 1380-1388, 2015.

[43] C. Benz and S. Seebacher, "Open Innovation in Ecosystems - A Service Science Perspective on Open Innovation," in Exploring Service Science, LNBIP, pp. 112-124, 2018.

[44] J. Spohrer, P. P. Maglio, J. Bailey, and D. Gruhl, "Steps toward a science of service systems," Computer, vol. 40, no. 1, pp. 71-77, 2007.

[45] J. West, A. Salter, W. Vanhaverbeke, and H. Chesbrough, "Open innovation: The next decade," Open Innovation: New Insights and Evidence, vol. 43, pp. 805-811, June 2014.

[46] A. Gawer and M. A. Cusumano, "Industry Platforms and Ecosystem Innovation," Journal of Product Innovation Management, vol. 31, no. 3, pp. 417-433, 2014.

[47] M. Ceccagnoli, C. Forman, P. Huang, and D. J. Wu, "Cocreation of Value in a Platform Ecosystem! The Case of Enterprise Software," MIS Quarterly, vol. 36, no. 1, pp. 263-290, 2012.

[48] G. Parker and M. Van Alstyne, "Innovation, Openness, and Platform Control," Management Science, vol. 64, no. 7, pp. 3015-3032, 2017.

[49] T. Enders, C. Benz, R. Schüritz, and P. Lujan in ECIS, (Online AIS Conference), pp. 1-16, 2020.

[50] T. Enders, C. Wolff, and G. Satzger, "Knowing What to Share: Selective Revealing in Open Data," in ECIS, (Online AIS Conference), pp. 1-12, 2020.

[51] P. Jen-Hwa Hu, H. Han-fen, and F. Xiao, "Examining the Mediating Roles of Cognitive Load and Performance Outcomes in User Satisfaction with a Website: A Field Quasi-Experiment," MIS Quarterly, vol. 41, no. 3, pp. 975-988, 2017.

[52] A. Islam, M. Mäntymäki, and A. Bhattacherjee, "Towards a Decomposed Expectation Confirmation Model of It Continuance: The Role of Usability," Communications of the Association for Information Systems, vol. 40, pp. 502-523, 2017.

[53] J. Sweller, "Cognitive Load During Problem Solving: Effects on Learning," Cognitive science, vol. 12, no. 2, pp. 257-285, 1988.

[54] W. Wang and I. Benbasat, "Empirical Assessment of Alternative Designs for Enhancing Different Types of Trusting Beliefs in Online Recommendation Agents," Journal of Management Information Systems, vol. 33, no. 3, pp. 744-775, 2016.

[55] T. Miller, "Explanation in Artificial Intelligence: Insights From the Social Sciences," Artificial Intelligence, vol. 267, pp. 1-38, 2019.

[56] C. Rzepka and B. Berger, "User Interaction With AI-Enabled Systems: A Systematic Review of Is Research," in ICIS, 2018. 